\title{
Solution-Processed TiO2-Based Schottky Diodes with a Large Barrier Height
}

DOI:

10.1109/LED.2019.2928007

\section{Document Version}

Accepted author manuscript

Link to publication record in Manchester Research Explorer

\section{Citation for published version (APA):}

Zhang, X., Cai, W., Zhang, J., Brownless, J., Wilson, J., Zhang, Y., \& Song, A. (2019). Solution-Processed TiO2Based Schottky Diodes with a Large Barrier Height. IEEE Electron Device Letters, 1-1.

https://doi.org/10.1109/LED.2019.2928007

\section{Published in:}

IEEE Electron Device Letters

\section{Citing this paper}

Please note that where the full-text provided on Manchester Research Explorer is the Author Accepted Manuscript or Proof version this may differ from the final Published version. If citing, it is advised that you check and use the publisher's definitive version.

\section{General rights}

Copyright and moral rights for the publications made accessible in the Research Explorer are retained by the authors and/or other copyright owners and it is a condition of accessing publications that users recognise and abide by the legal requirements associated with these rights.

\section{Takedown policy}

If you believe that this document breaches copyright please refer to the University of Manchester's Takedown Procedures [http://man.ac.uk/04Y6Bo] or contact uml.scholarlycommunications@manchester.ac.uk providing relevant details, so we can investigate your claim.

\section{OPEN ACCESS}




\title{
Solution-Processed $\mathrm{TiO}_{2}$-Based Schottky Diodes with a Large Barrier Height
}

\author{
Xijian Zhang, Wensi Cai, Jiawei Zhang, Joseph Brownless, Joshua Wilson, Yifei Zhang, and Aimin \\ Song, Senior Member, IEEE
}

\begin{abstract}
Thin-film Schottky diodes are one of the key elements in large-area flexible electronics. In such devices, a highly uniform semiconductor film is vital for the device performance. Here we propose a novel solution-based anodization method to form a conformal oxide semiconductor layer for Schottky diodes. The thickness of the anodized $\mathrm{TiO}_{2}$ layer varied from 12 to $22.5 \mathrm{~nm}$. The optimized $\mathrm{Pt} / \mathrm{TiO}_{2} / \mathrm{Ti}$ Schottky diode demonstrated a large barrier height of $1.19 \mathrm{eV}$, an on/off ratio as high as $3.5 \times 10^{6}$ at $\pm 2 \mathrm{~V}$, and an ideality factor of 1.5 . The average breakdown electric field was $5.5 \mathrm{MV} / \mathrm{cm}$, which is higher than typical values of conventional solution processed $\mathrm{TiO}_{2}$. The diode with a 15-nm-thick $\mathrm{TiO}_{2}$ layer also showed good rectification properties up to $0.7 \mathrm{MHz}$.
\end{abstract}

Index Terms-Schottky diode, $\mathrm{TiO}_{2}$, anodization, high frequency.

\section{INTRODUCTION}

$\mathrm{T}$ ITANIUM oxide $\left(\mathrm{TiO}_{2}\right)$ is a popular material due to its high permittivity, superior chemical stability and high optical transmittance in the visible-IR spectral range [1]. Such properties make $\mathrm{TiO}_{2}$ widely used in applications such as gas and humidity sensors [2], solar cells [3] and photoelectrochromic cells [4]. Schottky contacts can be formed between titanium oxide and a high work function metal [5]. The barrier heights of $\mathrm{TiO}_{2}$-based Schottky diodes can be tuned sensitively by the introduction of hydrogen, making these diodes applicable as hydrogen sensors [6]. $\mathrm{TiO}_{2}$-based Schottky diodes are also used to produce steady-state current flow in the steady-state catalytic reactions [7]. Under irradiation of 350-nm UV light, a high responsivity of $3.1 \mathrm{~A} / \mathrm{W}$ was obtained by $\mathrm{TiO}_{2}$ Schottky diode-based UV detectors [8]. However, most of the reported $\mathrm{TiO}_{2}$ Schottky diodes exhibited large reverse leakage currents and small rectification ratios, which limit the use of $\mathrm{TiO}_{2}$ in thin-film electronics [9]-[11].

There are several methods to produce $\mathrm{TiO}_{2}$ films including

This work was supported in part by the Engineering and Physical Sciences Research Council (EPSRC) under Grant EP/N021258/1, in part by the National Key Research and Development Program of China under Grant 2016YFA0301200, in part by the National Natural Science Foundation of China under Grant 11374185 and Grant 11304180, and in part by the China Scholarship Council (CSC) under Grant 201706225077. (Corresponding author: Aimin Song.)

X. Zhang and Y. Zhang are with the Center of Nanoelectronics, School of Microelectronics, Shandong University, Jinan 250100, China.

W. Cai, J. Zhang, J. Brownless, J. Wilson, and A. Song are with the School of Electrical and Electronic Engineering, The University of Manchester, Manchester M13 9PL, U.K. (e-mail: a.song@manchester.ac.uk). chemical vapor deposition (CVD) [12], pulsed laser deposition (PLD) [13], atomic layer deposition (ALD) [14], electron-beam evaporation [15] and thermally oxidizing titanium [16]. Compared to these methods, anodization is one of the most promising techniques, because it is simple, fast, suitable for large-area electronics and does not need vacuum technologies [17]. Most studies of $\mathrm{TiO}_{2}$-based Schottky diodes fabricated by anodization so far focused on porous or nanotube structures to obtain highly active surface and high surface to volume ratio [18]-[20]. This paper reports on anodized conformal $\mathrm{TiO}_{2}$ layer with high uniformity and $\mathrm{TiO}_{2}$-based Schottky didoes with high performance. Capacitance-voltage and current-voltage measurements were performed to study the electrical characteristics of the $\mathrm{TiO}_{2}$ Schottky diodes. The high-frequency characteristics of the $\mathrm{TiO}_{2}$ Schottky didoes were measured in a single-stage rectifier circuit. Due to the simple preparation process and excellent electrical properties, the low-voltage anodized $\mathrm{TiO}_{2}$ Schottky diodes offer a wide range of potential applications in the electronics and optoelectronics.

\section{EXPERIMENTS}

The $\mathrm{Pt} / \mathrm{TiO}_{2} / \mathrm{Ti}$ Schottky diodes shown in Fig. 1(a) were fabricated on Corning 7059. Titanium film with a thickness of $100 \mathrm{~nm}$ was deposited onto the glass substrates using RF magnetron sputtering. An Ar pressure of 1.2 $\mathrm{Pa}$ and a RF power of $30 \mathrm{~W}$ were utilized to deposit Ti. Then the titanium film was anodized in a $10^{-3} \mathrm{~mol} / \mathrm{L}$ citric acid solution using a gold wire as the cathode at room temperature. A Keithley 2400 Source Measure Unit supplied a constant current of $0.2 \mathrm{~mA} / \mathrm{cm}^{2}$. $\mathrm{TiO}_{2}$ films were anodized at $8 \mathrm{~V}, 10 \mathrm{~V}, 12 \mathrm{~V}$ and $15 \mathrm{~V}$, respectively. Finally, a circular Pt pad of a radius of $180 \mu \mathrm{m}$ and a thickness of $50 \mathrm{~nm}$ was deposited by RF magnetron sputtering to form the Schottky anode. Atomic force microscope (AFM) images were obtained by using Bruker Dimension FastScan. The thickness of the titanium oxide was measured using a Woollam M-2000 Ellipsometer. Current-voltage $(J-V)$ and breakdown characteristics were examined by using an Agilent E5270B semiconductor analyzer. Capacitance-voltage (C-V) characteristics were measured by using an Agilent E4980A LCR meter. High frequency measurements were performed by using a HP 8116A pulse/function generator and an Agilent 34411A digit multimeter. The elemental constitutes of $\mathrm{TiO}_{2}$ films were examined by X-ray photoelectron spectroscopy (XPS) with ThermoFisher Scientific ESCALAB 250. 


\section{RESULTS AND DISCUSSIONS}

The key structure of the proposed diode is the Schottky contact between $\mathrm{Pt}$ and $\mathrm{TiO}_{2}$, so a smooth surface of anodized titanium oxide is a critical prerequisite. A porous structure can be formed with a high anodizing voltage [21] which is avoided here. Fig. 1(b) shows an AFM image of $15 \mathrm{~V}$ anodized titanium oxide. The surface is smooth and uniform with an RMS roughness of $0.38 \mathrm{~nm}$, showing no porous structure. $15 \mathrm{~V}$ is the highest anodizing voltage used in this work, and all the titanium oxide films anodized at lower voltages did not show a porous or nanotube structure either. The smooth surface results from the low concentration and weak acidity of citric acid, the low voltages and short times of anodization [22]. The thicknesses of titanium oxide anodized at different voltages can be estimated by the ratio $1.5 \mathrm{~nm} / \mathrm{V}$ [23]. Measured by an ellipsometry, the actual thicknesses of titanium oxide anodized at $10 \mathrm{~V}$ and $15 \mathrm{~V}$ were $15.6 \mathrm{~nm}$ and $24.7 \mathrm{~nm}$, showing a good agreement with the estimation. (a)

(b)

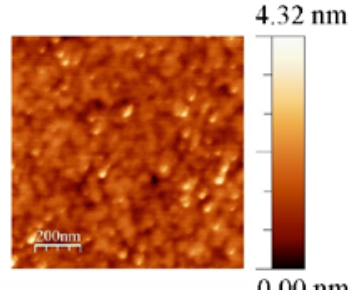

(c)

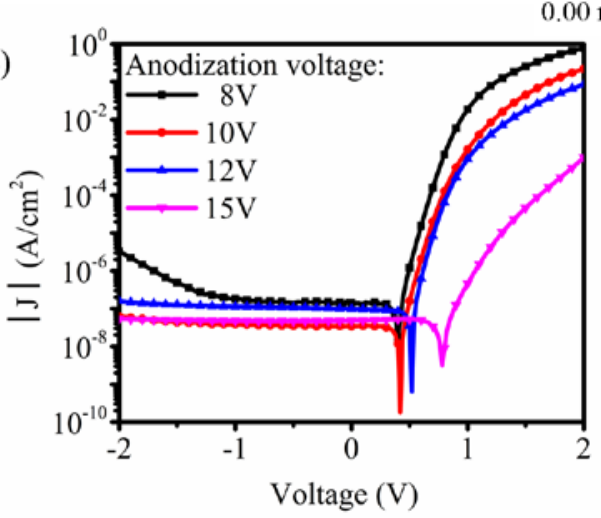

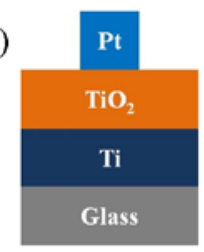

Fig. 1. (a) Schematic cross-sectional view of the $\mathrm{TiO}_{2}$ Schottky diodes. (b) AFM micrograph of $\mathrm{TiO}_{2}$ anodized at $15 \mathrm{~V}$. (c) Current density as a function of bias voltage $(J-V)$ of the $\mathrm{TiO}_{2}$ Schottky diodes fabricated with different anodization voltages.

The solution-processed method is suitable for large area fabrication. The size of every sample is $2 \mathrm{~cm} \times 1 \mathrm{~cm}$, and there are 36 diodes on each sample. The performance of all diodes on a sample are very similar. For instance, the standard deviation of the barrier height is $\sim 1.3 \%$, and the standard deviation of the ideality factor is $\sim 4.5 \%$. Fig. 1 (c) shows the current density as a function of voltage curves of the Schottky diodes anodized at different voltages. The diode anodized at $8 \mathrm{~V}$ has the highest forward current and the highest reverse current. The large leakage current can be attributed to the small thickness of the titanium oxide and inhomogeneity in the Schottky barrier height [24]. At anodization voltage $>10 \mathrm{~V}$, i.e. thicknesses larger than $15 \mathrm{~nm}$, the reverse current is reduced to $<10^{-7}$ $\mathrm{A} / \mathrm{cm}^{2}$, which agrees with the previously reported result when anodized $\mathrm{TiO}_{2}$ was used as the gate dielectric in thin film transistors [23]. The performance of the diode significantly deteriorates when the anodizing voltage reaches $15 \mathrm{~V}$. The forward current decreases because the series resistance $\left(R_{\mathrm{S}}\right)$ significantly increases as shown in Tab. I.

TABLE I

Parameters of the Proposed SchottKy Diodes ANodized at Different VOLTAGES

\begin{tabular}{ccccccc}
\hline \hline $\begin{array}{c}\text { Anodization } \\
\text { voltage }(\mathrm{V})\end{array}$ & $\mathrm{n}$ & $\begin{array}{c}\Phi_{\mathrm{B}} \\
(\mathrm{eV})\end{array}$ & $\begin{array}{c}\Phi_{\mathrm{bi}} \\
(\mathrm{eV})\end{array}$ & $\mathrm{I}_{\mathrm{on} / \mathrm{off}}$ & $\begin{array}{c}\mathrm{R}_{\mathrm{S}} \\
(\mathrm{k} \Omega)\end{array}$ & $\begin{array}{c}\text { O:Ti } \\
\text { Atomic ratio }\end{array}$ \\
\hline 8 & 1.5 & 1.14 & 0.87 & $2.4 \times 10^{5}$ & 0.7 & 2.8 \\
10 & 1.5 & 1.19 & 1.00 & $3.5 \times 10^{6}$ & 2.1 & 2.4 \\
12 & 1.5 & 1.23 & 1.15 & $5.3 \times 10^{5}$ & 5.2 & 2.6 \\
15 & 2.9 & 1.18 & 2.45 & $1.9 \times 10^{4}$ & 116.5 & 2.5 \\
\hline \hline
\end{tabular}

The ideality factor $n$, effective barrier height $\Phi_{\mathrm{B}}$, rectification ratio $I_{\mathrm{on} / \mathrm{off}}$ and series resistance $R_{\mathrm{S}}$ can be extracted from the current density versus voltage curves [25] and are shown in Tab. I. Excluding the diode anodized at $15 \mathrm{~V}$ for its bad performance, the barrier height $\Phi_{\mathrm{B}}$ and series resistance $R_{\mathrm{S}}$ of the diodes increase linearly with increasing anodizing voltage. The diode anodized at $10 \mathrm{~V}$ has the highest rectification ratio $I_{\text {on/off }}$ of $3.5 \times 10^{6}$, which benefits from the lowest reverse current. The lowest reverse current may be attributed to the smallest inhomogeneity in the Schottky barrier height between Pt and $\mathrm{TiO}_{2}$ [24]. The elemental constitutes of $\mathrm{TiO}_{2}$ films were obtained by XPS measurement. The O:Ti atomic ratios of all $\mathrm{TiO}_{2}$ films are greater than 2, which may be related to hydroxyl groups appeared in the $\mathrm{TiO}_{2}$ films during anodization. The diode anodized at $10 \mathrm{~V}$ has the lowest $\mathrm{O}: \mathrm{Ti}$ atomic ratio and the highest $\mathrm{I}_{\mathrm{on} / \mathrm{off}}$.

TABLE II

COMPARISONS OF BARRIER HEIGHT BETWEEN OUR WORK AND OTHER DiODES IN PUBLICATIONS

\begin{tabular}{|c|c|c|c|}
\hline References & Electrode & Semiconductor & $\begin{array}{c}\text { Barrier height } \\
(\mathrm{eV})\end{array}$ \\
\hline$[26]$ & $\mathrm{Pt}$ & $\mathrm{IGZO}$ & 0.79 \\
\hline$[27]$ & $\mathrm{TiW}$ & $\mathrm{InP}$ & 0.83 \\
\hline$[8]$ & $\mathrm{Ag}$ & $\mathrm{TiO}_{2}$ & 0.85 \\
\hline$[13]$ & $\mathrm{CS}-\mathrm{AFM}$ & $\mathrm{TiO}_{2}$ & 0.50 \\
\hline$[28]$ & $\mathrm{Pt}$ & $\mathrm{TiO}_{2}$ & 1.05 \\
\hline$[16]$ & $\mathrm{Si}$ & $\mathrm{TiO}_{2}$ & 0.73 \\
\hline This work & $\mathrm{Pt}$ & $\mathrm{TiO}_{2}$ & $1.14-1.23$ \\
\hline
\end{tabular}

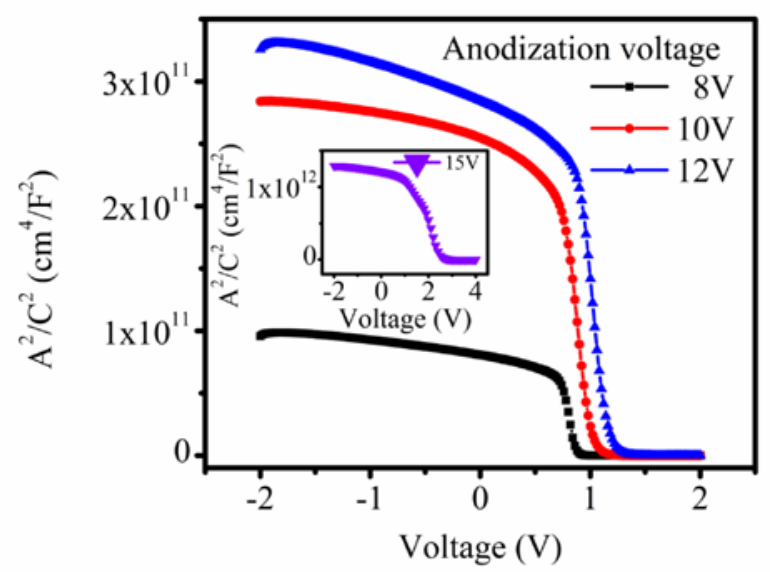

Fig. 2. Capacitance versus voltage characteristics of the Schottky diodes anodized at different voltages. The inset is the curve of the diode anodized at $15 \mathrm{~V}$, shown separately due to its bigger range.

It should be noted that the barrier heights of our $\mathrm{TiO}_{2}$ 
Schottky diodes fabricated by anodization, from $1.14 \mathrm{eV}$ to $1.23 \mathrm{eV}$, are much larger than those diodes reported previously which are shown in Tab. II.

Capacitance measurement using $1 \mathrm{kHz}$ frequency was also carried out to confirm the trend of the barrier heights. The capacitance versus voltage $(\mathrm{C}-\mathrm{V})$ characteristics of the Schottky diodes anodized at different voltages are shown in Fig. 2. The built-in potential $\left(V_{\mathrm{bi}}\right)$ of the Schottky diodes anodized at different voltage can be obtained from Fig. 2 and are shown in Tab. I. Except the diode anodized at $15 \mathrm{~V}$, the built-in potentials $V_{\text {bi }}$ is smaller than the barrier height $\Phi_{\mathrm{B}}$ and linearly increases from $0.87 \mathrm{eV}$ to $1.15 \mathrm{eV}$ with the increasing anodizing voltage. The trend of the built-in potential $V_{\text {bi }}$ agrees with that of barrier height $\Phi_{\mathrm{B}}$.

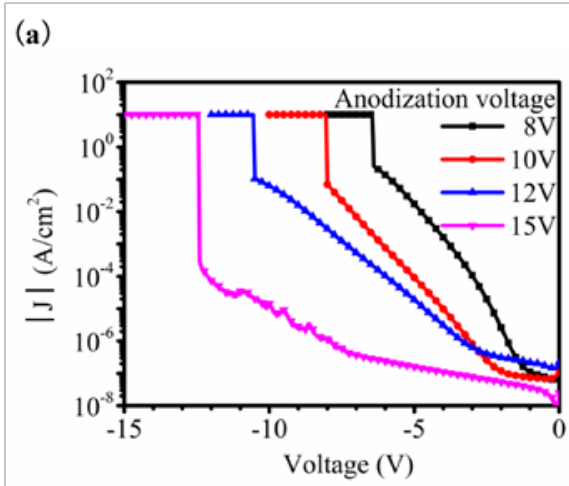

(b)

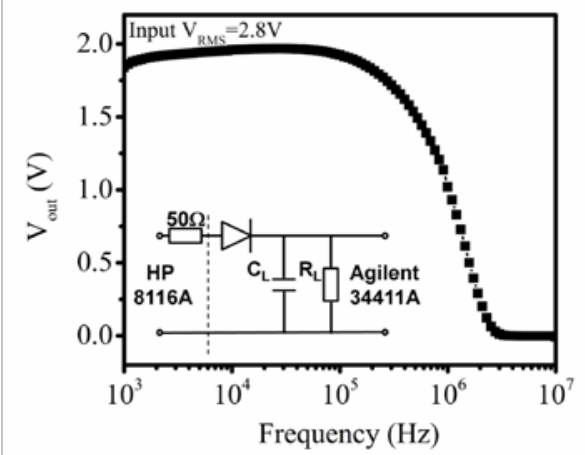

Fig. 3. (a) Breakdown measurements of the Schottky diodes with different anodization voltage. (b) Frequency response of a Schottky diode anodized at $10 \mathrm{~V}$. The inset shows the measurement circuit.

The breakdown voltage is one of the key performance parameters for Schottky diodes [12]. Fig. 3(a) shows the measured breakdown characteristics. The breakdown voltage becomes larger as the anodizing voltage increases. The devices anodized at 8, 10, 12, $15 \mathrm{~V}$, break down at 6.5, 8.1, 10.6 and $12.5 \mathrm{~V}$, respectively. The breakdown electric field strengths in all devices are similar with an averaged value of $5.5 \mathrm{MV} / \mathrm{cm}$.

The frequency response of the diode is characterized by applying a sinusoidal signal and measuring the output DC voltage as shown in the inset of Fig. 3(b). Fig. 3(b) shows the measured frequency response of the diode anodized at $10 \mathrm{~V}$. The input root mean square voltage $\left(V_{\mathrm{RMS}}\right)$ is $2.8 \mathrm{~V}$, the output load is a $10 \mathrm{M} \Omega$ resistance $\left(R_{\mathrm{L}}\right)$ in parallel with a $100 \mathrm{nF}$ capacitance $\left(C_{\mathrm{L}}\right)$. The measured cut-off frequency is $700 \mathrm{kHz}$, and the diode still produces a DC output voltage of $1 \mathrm{~V}$ at 1 $\mathrm{MHz}$.

\section{CONCLUSION}

In summary, high-performance Schottky diodes with $\mathrm{TiO}_{2}$ anodized at different voltages were fabricated on glass substrate. The diode anodized at $10 \mathrm{~V}$ exhibited a high rectification ratio of $3.5 \times 10^{6}$ and a large barrier height of $1.19 \mathrm{eV}$. The $\mathrm{TiO}_{2}$ semiconductor film and Schottky diodes, as well as other similar materials and devices, produced by such simple solution process may have useful implications in development of thin-film electronics.

\section{REFERENCES}

[1] G. D. Wilk, R. M. Wallace, and J. M. Anthony, "High-к gate dielectrics: Current status and materials properties considerations,” J. Appl. Phys., vol. 89, no. 10, pp. 5243-5275, May 2001, doi: 10.1063/1.1361065.

[2] F. Hossein-Babaei and S. Rahbarpour, "Titanium and silver contacts on thermally oxidized titanium chip: Electrical and gas sensing properties," Solid-State Electron., vol. 56, no. 1, pp. 185-190, Feb. 2011, doi: 10.1016/j.sse.2010.12.007.

[3] T. S. Kang, A. P. Smith, B. E. Taylor, and M. F. Durstock, "Fabrication of Highly-Ordered $\mathrm{TiO}_{2}$ Nanotube Arrays and Their Use in Dye-Sensitized Solar Cells,” Nano Lett., vol. 9, no. 2, pp. 601-606, Feb. 2009, doi: 10.1021/nl802818d.

[4] C. Bechinger, S. Ferrere, A. Zaban, J. Sprague, and B. A. Gregg, "Photoelectrochromic windows and displays," Nature, vol. 383, no. 6601, pp. 608-610, Oct. 1996, doi: 10.1038/383608a0.

[5] H. Kobayashi, K. Kishimoto, and Y. Nakato, "Reactions of hydrogen at the interface of palladium-titanium dioxide Schottky diodes as hydrogen sensors, studied by workfunction and electrical characteristic measurements,” Surf. Sci., vol. 306, no. 3, pp. 393-405, Apr. 1994, doi: 10.1016/0039-6028(94)90080-9.

[6] S. Rahbarpour and K. Nemati, "Hydrogen Detection Mechanism in Schottky Type Ag-TiO ${ }_{2}$ Hydrogen Sensors," Sens. Lett., vol. 10, no. 3-4, pp. 874-878, Mar./Apr. 2012, doi: 10.1166/sl.2012.2589.

[7] X. Z. Ji, A. Zuppero, J. M. Gidwani, and G. A. Somorjai, "The catalytic nanodiode: Gas phase catalytic reaction generated electron flow using nanoscale platinum titanium oxide Schottky diodes," Nano Lett., vol. 5, no. 4, pp. 753-756, Apr. 2005, doi: 10.1021/nl050241a.

[8] H. F. Zhang, S. P. Ruan, H. L. Li, M. Zhang, K. Lv, and C. H. Feng, "Schottky Diode Ultraviolet Detector Based on $\mathrm{TiO}_{2}$ Nanowire Array," IEEE Electron Device Lett., vol. 33, no. 1, pp. 83-85, Jan. 2012, doi: 10.1109/led.2011.2173896.

[9] Y. Alivov, Y. C. Ding, V. Singh, and P. Nagpal, "Titanium-dioxide nanotube p-n homojunction diode,” Appl. Phys. Lett., vol. 105, no. 26, p. 263501, Dec. 2014, doi: 10.1063/1.4905218.

[10] Y. C. Leem, O. Seo, Y. R. Jo, J. H. Kim, J. Chun, B. J. Kim, D. Y. Noh, W. Lim, Y. L. Kim, and S. J. Park, "Titanium oxide nanotube arrays for high light extraction efficiency of GaN-based vertical light-emitting diodes," Nanoscale, vol. 8, no. 19, pp. 10138-10144, Apr. 2016, doi: 10.1039/c6nr00503a.

[11] S. B. Herner, A. D. Weerakkody, A. Belkadi, and G. Moddel, "High performance MIIM diode based on cobalt oxide/titanium oxide,” Appl. Phys. Lett., vol. 110, no. 22, p. 223901, May 2017, doi: 10.1063/1.4984278.

[12] H. S. Kim, D. C. Gilmer, S. A. Campbell, and D. L. Polla, "Leakage current and electrical breakdown in metal-organic chemical vapor deposited $\mathrm{TiO}_{2}$ dielectrics on silicon substrates,” Appl. Phys. Lett., vol. 69, no. 25, pp. 3860-3862, Dec. 1996, doi: 10.1063/1.117129.

[13] E. Gyoergy, A. P. del Pino, G. Sauthier, A. Figueras, F. Alsina, and J. Pascual, "Structural, morphological and local electric properties of $\mathrm{TiO}_{2}$ thin films grown by pulsed laser deposition,” J. Phys. D: Appl. Phys., vol. 40, no. 17, pp. 5246-5251, Sep. 2007, doi: 10.1088/0022-3727/40/17/035.

[14] W. Y. Park, G. H. Kim, J. Y. Seok, K. M. Kim, S. J. Song, M. H. Lee, and C. S. Hwang, "A Pt/TiO $/ / \mathrm{Ti}$ Schottky-type selection diode for alleviating the sneak current in resistance switching memory arrays," Nanotechnology, vol. 21, no. 19, p. 195201, May 2010, doi: 10.1088/0957-4484/21/19/195201.

[15] V. M. Arakelyan, V. E. Galstyan, K. S. Martirosyan, G. E. Shahnazaryan, V. M. Aroutiounian, and P. G. Soukiassian, "Hydrogen sensitive gas sensor based on porous silicon/TiO ${ }_{2-x}$ structure," Physica E, vol. 38, no. 1, pp. 219-221, Apr. 2007, doi: 10.1016/j.physe.2006.12.037. 
[16] L. H. Chong, K. Mallik, C. H. de Groot, and R. Kersting, "The structural and electrical properties of thermally grown $\mathrm{TiO}_{2}$ thin films," J. Phys.: Condens. Matter., vol. 18, no. 2, pp. 645-657, Jan. 2006, doi: 10.1088/0953-8984/18/2/020.

[17] S. Farsinezhad, T. shanavas, N. Mahdi, A. M. Askar, P. Kar, H. Sharma, and K. Shankar, "Core-shell titanium dioxide-titanium nitride nanotube arrays with near-infrared plasmon resonances," Nanotechnology, vol. 29, no. 15, p. 154006, Apr. 2018, doi: 10.1088/1361-6528/aaad58.

[18] A. Z. Sadek, H. D. Zheng, K. Latham, W. Wlodarski, and K. Kalantar-Zadeh, "Anodization of Ti Thin Film Deposited on ITO," Langmuir, vol. 25, no. 1, pp. 509-514, Jan. 2009, doi: 10.1021/la802456r.

[19] C. Richter and C. A. Schmuttenmaer, "Exciton-like trap states limit electron mobility in $\mathrm{TiO}_{2}$ nanotubes," Nat. Nanotechnol., vol. 5, no. 11, pp. 769-772, Nov. 2010, doi: 10.1038/nnano.2010.196.

[20] M. Hattori, K. Noda, T. Nishi, K. Kobayashi, H. Yamada, and K. Matsushige, "Investigation of electrical transport in anodized single $\mathrm{TiO}_{2}$ nanotubes,” Appl. Phys. Lett., vol. 102, no. 4, p. 043105, Jan. 2013, doi: 10.1063/1.4789763.

[21] Z. Hu, Q. Zhang, J. Gao, Z. Liu, J. Zhai, and L. Jiang, "Photocatalysis-Triggered Ion Rectification in Artificial Nanochannels Based on Chemically Modified Asymmetric $\mathrm{TiO}_{2}$ Nanotubes," Langmuir, vol. 29, no. 15, pp. 4806-4812, Apr. 2013, doi: 10.1021/la400624p.

[22] R. Koole, P. Liljeroth, S. Oosterhout, and D. Vanmaekelberg, "Chemisorption determines the photovoltage of a $\mathrm{Ti} / \mathrm{TiO}_{2} / \mathrm{Au} / \mathrm{Dye}$ internal electron emission photovoltaic cell,” J. Phys. Chem. B, vol. 109, no. 19, pp. 9205-9208, May 2005, doi: 10.1021/jp051344k.

[23] L. A. Majewski, R. Schroeder, and M. Grell, "One volt organic transistor," Adv. Mater., vol. 17, no. 2, pp. 192-196, Jan. 2005, doi: 10.1002/adma.200400809.

[24] J. Wilson, J. W. Zhang, Y. P. Li, Y. M. Wang, Q. Xin, and A. M. Song, "Influence of interface inhomogeneities in thin-film Schottky diodes," Appl. Phys. Lett., vol. 111, no. 21, p. 213503, Nov. 2017, doi: 10.1063/1.5004247.

[25] Q. Xin, L. L. Yan, L. L. Du, J. W. Zhang, Y. Luo, Q. P. Wang, and A. M. Song, "Influence of sputtering conditions on room-temperature fabricated InGaZnO-based Schottky diodes,” Thin Solid Films, vol. 616, pp. 569-572, Oct. 2016, doi: 10.1016/j.tsf.2016.09.016.

[26] J. W. Zhang, Y. P. Li, B. L. Zhang, H. B. Wang, Q. Xin, and A. M. Song, "Flexible indium-gallium-zinc-oxide Schottky diode operating beyond 2.45 GHz,” Nat. Commun., vol. 6, p. 7561, Jul. 2015, doi: 10.1038/ncomms8561.

[27] J. Chen, Q. Wang, J. Lv, H. Tang, and X. Li, “Current-voltage-temperature and capacitance-voltage-temperature characteristics of TiW alloy/p-InP Schottky barrier diode,” J. Alloys Compd., vol. 649, pp. 1220-1225, Nov. 2015, doi: 10.1016/j.jallcom.2015.07.239.

[28] S. K. Kim, G. J. Choi, S. Y. Lee, M. Seo, S. W. Lee, J. H. Han, H. S. Ahn, S. Han, and C. S. Hwang, "Al-doped $\mathrm{TiO}_{2}$ films with ultralow leakage currents for next generation DRAM capacitors," Adv. Mater., vol. 20, no. 8, pp. 1429-1435, Apr. 2008, doi: 10.1002/adma.200701085. 